\title{
A vibrational spectroscopic study of the silicate mineral plumbophyllite $\mathrm{Pb}_{2} \mathrm{Si}_{4} \mathrm{O}_{10} \cdot \mathrm{H}_{2} \mathrm{O}$
}

\author{
Ray L. Frost ${ }^{\mathrm{a}, *}$, Andrés López ${ }^{\mathrm{a}}$, Yunfei Xi ${ }^{\mathrm{a}}$, Ricardo Scholz ${ }^{\mathrm{b}}$, Cristiano Lana ${ }^{\mathrm{b}}$

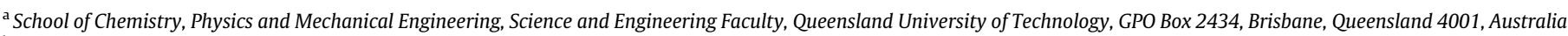 \\ ${ }^{\mathrm{b}}$ Geology Department, School of Mines, Federal University of Ouro Preto, Campus Morro do Cruzeiro, Ouro Preto, MG 35,400-00, Brazil
}

\section{H I G H L I G H T S}

-We have studied the silicate mineral plumbophyllite $\mathrm{Pb}_{2} \mathrm{Si}_{4} \mathrm{O}_{10} \cdot \mathrm{H}_{2} \mathrm{O}$.

- The structure consists of undulating sheets of silicate tetrahedra.

- Raman and infrared bands are attributed to stretching and bending vibrations of $\left(\mathrm{SiO}_{3}\right)_{n}$ units.

- Multiple water stretching and bending modes shows much variation in hydrogen bonding.

\section{G R A P H I C A L A B S T R A C T}

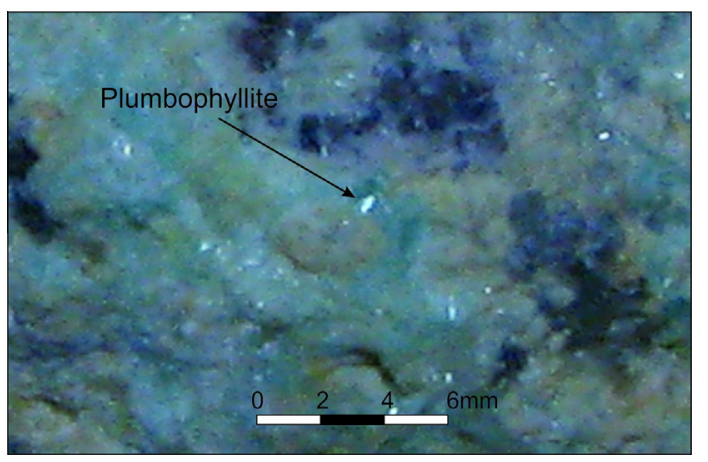

\section{A R T I C L E I N F O}

\section{Article history:}

Received 16 December 2013

Received in revised form 24 February 2014

Accepted 25 February 2014

Available online 12 March 2014

\section{Keywords:}

Plumbophyllite

Silicate

Apophyllite

Pentagonite

Raman spectroscopy

Molecular water

\begin{abstract}
A B S T R A C T
Raman spectroscopy complimented with infrared spectroscopy has been used to study the molecular structure of the mineral of plumbophyllite. The Raman spectrum is dominated by a very intense sharp peak at $1027 \mathrm{~cm}^{-1}$, assigned to the $\mathrm{SiO}$ stretching vibrations of $\left(\mathrm{SiO}_{3}\right)_{n}$ units. A very intense Raman band at $643 \mathrm{~cm}^{-1}$ is assigned to the bending mode of $\left(\mathrm{SiO}_{3}\right)_{n}$ units. Raman bands observed at 3215, 3443, 3470, 3494 and $3567 \mathrm{~cm}^{-1}$ are assigned to water stretching vibrations. Multiple water stretching and bending modes are observed showing that there is much variation in hydrogen bonding between water and the silicate surfaces. Because of the close similarity in the structure of plumbophyllite and apophyllite, a comparison of the spectra with that of apophyllites is made. By using vibrational spectroscopy an assessment of the molecular structure of plumbophyllite has been made.
\end{abstract}

(c) 2014 Elsevier B.V. All rights reserved.

\section{Introduction}

The mineral plumbophyllite [1,2] is a silicate mineral of formula $\mathrm{Pb}_{2} \mathrm{Si}_{4} \mathrm{O}_{10} \cdot \mathrm{H}_{2} \mathrm{O}$ and occurs as colourless to pale blue prismatic crystals to $3 \mathrm{~mm}$, with wedge-shaped terminations at the Blue Bell claims, about $11 \mathrm{~km}$ west of Baker, San Bernardino County, California. It is found in narrow veins in a highly siliceous hornfels

\footnotetext{
* Corresponding author. Tel.: +61 73138 2407; fax: +61 731381804 . E-mail address: r.frost@qut.edu.au (R.L. Frost).
}

in association with cerussite, chrysocolla, fluorite, goethite, gypsum, mimetite, opal, plumbotsumite, quartz, sepiolite, and wulfenite $[1,2]$.

The mineral is orthorhombic with space group Pbcn and cell parameters $a=13.2083(4), \quad b=9.7832(3), \quad c=8.6545(2) \AA$, $V=1118.33(5) \AA^{3}$ and $Z=4$. The structure consists of undulating sheets of silicate tetrahedra between which are located $\mathrm{Pb}$ atoms and channels containing $\mathrm{H}_{2} \mathrm{O}$ (and $\mathrm{Pb}^{2+}$ lone-pair electrons) $[1,2]$. The silicate sheets can be described as consisting of zigzag pyroxene-like $\left(\mathrm{SiO}_{3}\right)_{n}$ chains joined laterally into sheets with the 
unshared tetrahedral apices in successive chains pointed alternately up and down, a configuration also found in pentagonite $[1,2]$. The structure of plumbophyllite is somewhat similar to that of pentagonite. The silicate sheets in pentagonite, although based on the typical hexagonal mesh pattern of basal $\mathrm{O}$ atoms, has the same alternating up-and-down configuration of apical $\mathrm{O}$ atoms as plumbophyllite. The structure consists of adjacent tetrahedral sheets in both structures are bound together by relatively strong bonds between interlayer cations and the apical $\mathrm{O}$ atoms.

Cavansite and pentagonite [3] belong to the vanadium silicate minerals which show an open porous structure with very small micron sized holes. Cavansite and pentagonite, dimorphs of $\mathrm{Ca}(\mathrm{VO})\left(\mathrm{Si}_{4} \mathrm{O}_{10}\right) \cdot 4 \mathrm{H}_{2} \mathrm{O}$ represent novel, layered-silicate structure types. Zigzag pyroxene-like $\left(\mathrm{SiO}_{3}\right)_{n}$ chains, joined laterally into sheets parallel to the a-c plane, are present in both minerals with tetrahedral apices pointed alternately plus and minus along the $b$ axes [4]. The lateral linkage in cavansite results in a network of 4-fold and 8-fold rings, but in pentagonite the network is entirely made up of 6 -fold rings [4]. The vanadyl groups $\mathrm{VO}^{2+}$ and $\mathrm{Ca}^{2+}$ ions lie in mirror planes between the silicate layers and are coordinated alternately to pairs of tetrahedral apices along the chains on opposite sides of the mirror planes. $\mathrm{V}$ is in square-pyramid coordination, and $\mathrm{Ca}$ is in seven fold coordination in both structures Both infrared and Raman spectra of plumbophyllite were reported in the original paper by Kampf et al. [2]. However, little interpretation of the spectra was given. Sengupta et al. reported the infrared spectra of some natural Indian zeolites including apophyllite [5]. Sidorov [6] reported the Raman spectrum of apophyllite and identified $\mathrm{Si}_{2} \mathrm{O}_{5}^{2-}$ ions in the structure and confirm the presence of these ions in silicates with double rings and double chains or layers. Adams et al. [7] determined the single crystal Raman spectrum of an apophyllite mineral. Duval and Lecomte [8] used vibrational spectroscopy to determine the role of water in the apophyllite structure. Raman spectroscopy has proven very useful for the study of minerals [3,9-11]. Indeed, Raman spectroscopy has proven most useful for the study of diagenetically related minerals as often occurs with minerals containing silicate groups such as plumbophyllite, apophyllite-(KF) and apophyllite-(KOH) [9,12-16]. The objective of this research is to report the vibrational spectra of plumbophyllite and to relate the spectra to the molecular structure of the mineral.

\section{Experimental}

\section{Samples description and preparation}

The plumbophyllite sample studied in this work forms part of the collection of the Geology Department of the Federal University of Ouro Preto, Minas Gerais, Brazil, with sample code SAC-091. The sample is from the Blue Bell mine, USA, type locality for the mineral. It is noted that the sample used in this work is identical to that used by Kampf et al. [2].

The sample was gently crushed and the associated minerals were removed under a stereomicroscope Leica MZ4. The plumbophyllite studied in this work occurs in association with unidentified clay mineral. Scanning electron microscopy (SEM) in the EDS mode was applied to support the mineral characterization.

\section{Scanning electron microscopy (SEM)}

Experiments and analyses involving electron microscopy were performed in the Center of Microscopy of the Universidade Federal de Minas Gerais, Belo Horizonte, Minas Gerais, Brazil (http:// www.microscopia.ufmg.br).

Plumbophyllite crystals were coated with a $5 \mathrm{~nm}$ layer of evaporated carbon. Secondary Electron and Backscattering Electron images were obtained using a JEOL JSM-6360LV equipment. Qualitative and semi-quantitative chemical analyses in the EDS mode were performed with a ThermoNORAN spectrometer model Quest and was applied to support the mineral characterization.

\section{Raman spectroscopy}

The crystals of plumbophyllite were placed and oriented on the stage of an Olympus BHSM microscope, equipped with $10 \times$ and $50 \times$ objectives and part of a Renishaw 1000 Raman microscope system, which also includes a monochromator, a filter system and a Charge Coupled Device (CCD). Raman spectra were excited by a HeNe laser $(633 \mathrm{~nm})$ at a nominal resolution of $2 \mathrm{~cm}^{-1}$ in the range between 100 and $4000 \mathrm{~cm}^{-1}$. Details of the experimental procedure have been published. The spatial resolution of the instrument is $1 \mu \mathrm{m}$. Thus, if crystals are less than this value, a mixture of crystals will be measured. However, the crystals of plumbophyllite used in this experiment were $>1.1 \mu \mathrm{m}$.

It is noted that there is a spectrum of plumbophyllite on the RRUFF data base. The spectrum has been downloaded and is given in the supplementary information for the purposes of comparison. It is noted that the spectrum differs from the work reported in this paper and also differs from the work reported by Kampf et al. [2].

Spectral manipulation such as baseline adjustment, smoothing and normalisation were performed using the Spectracalc software package GRAMS (Galactic Industries Corporation, NH, USA). Band component analysis was undertaken using the Jandel 'Peakfit' software package which enabled the type of fitting function to be selected and allows specific parameters to be fixed or varied accordingly. Band fitting was done using a Lorentz-Gauss crossproduct function with the minimum number of component bands used for the fitting process. The Gauss-Lorentz ratio was maintained at values greater than 0.7 and fitting was undertaken until reproducible results were obtained with squared correlations of $r^{2}$ greater than 0.995 .

\section{Results and discussion}

\section{Chemical characterization}

The SEM/BSI image of the plumbophyllite crystal fragment studied in this work is shown in Fig. 1. The sample occurs in association with unidentified clay mineral. A perfect cleavage can be observed. Qualitative chemical analysis of plumbophyllite shows a $\mathrm{Pb}$ silicate with minor amount of Zn (Fig. 2).

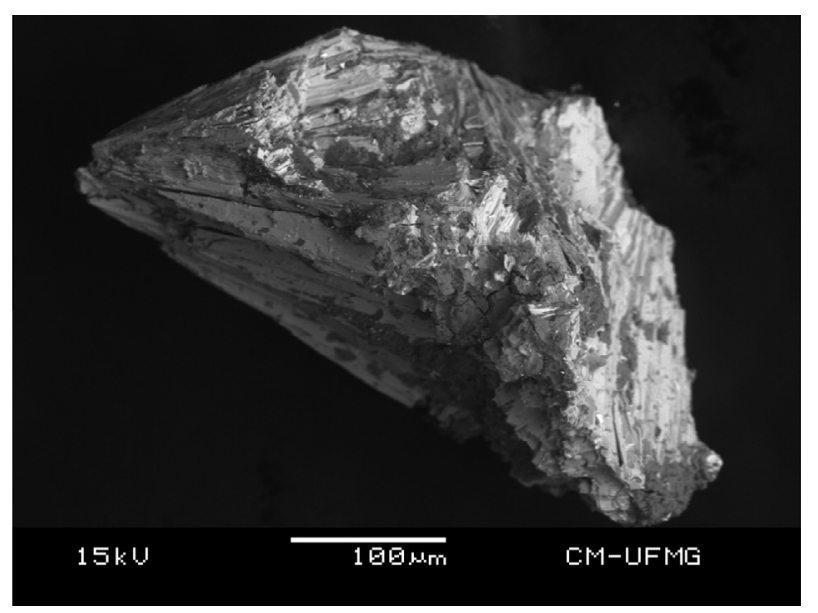

Fig. 1. Backscattered electron image (BSI) of a plumbophyllite crystal aggregate up to $0.5 \mathrm{~mm}$ in length. 


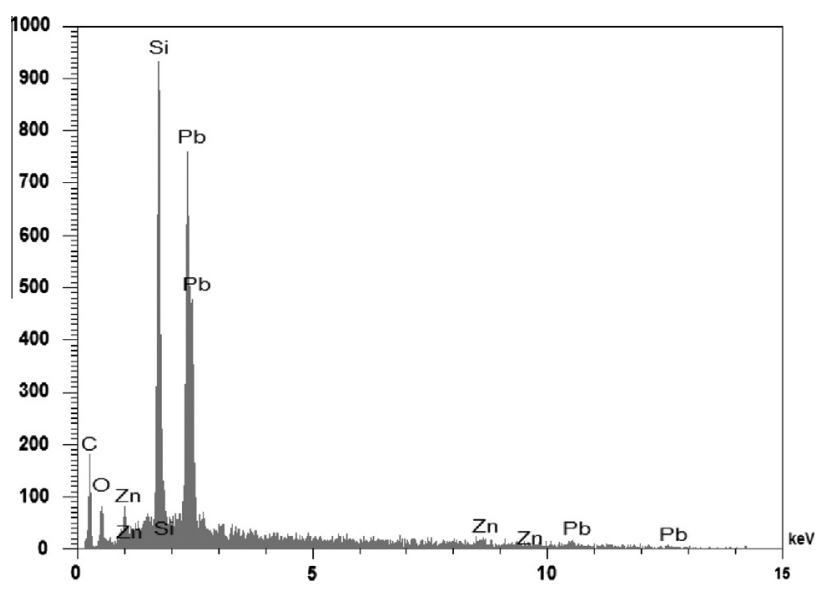

Fig. 2. EDS analysis of plumbophyllite.

\section{Vibrational spectroscopy of plumbophyllite}

The Raman spectrum of plumbophyllite in the $4000-100 \mathrm{~cm}^{-1}$ spectral range is illustrated in Fig. 3a. This spectrum displays the position and relative intensity of the Raman bands. It is noteworthy that there are large parts of the spectrum where no Raman intensity is observed. Therefore, the spectrum is subdivided into sections based upon the type of vibration being analyzed. In a similar fashion, the infrared spectrum of plumbophyllite over the $4000-500 \mathrm{~cm}^{-1}$ spectral range is reported in Fig. $3 \mathrm{~b}$. This spectrum shows the position and relative intensity of the infrared bands of plumbophyllite. A comparison between the Raman and infrared
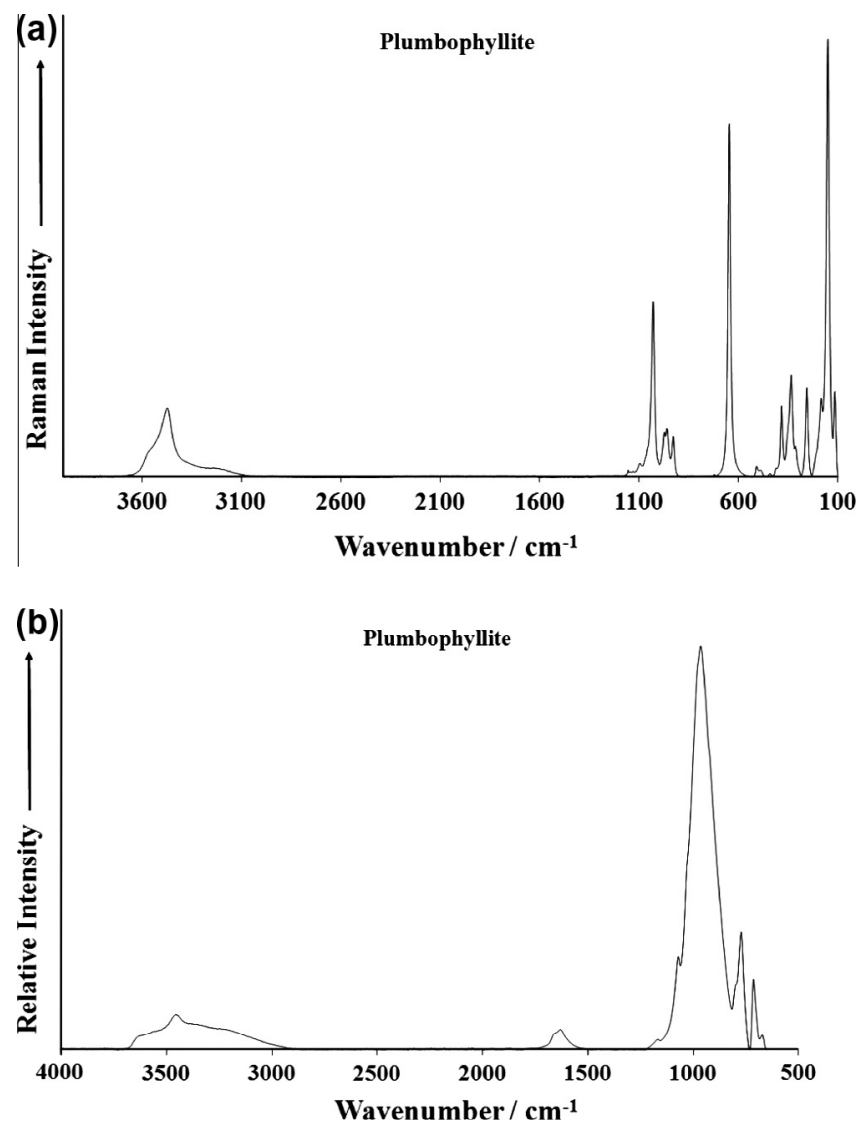

Fig. 3. (a) Raman spectrum of plumbophyllite over the $4000-100 \mathrm{~cm}^{-1}$ spectral range and (b) Infrared spectrum of plumbophyllite over the $4000-500 \mathrm{~cm}^{-1}$ spectral range. spectra may be made. Because of the lack of intensity in the infrared spectrum between for example $3000-2000 \mathrm{~cm}^{-1}$ spectral range, the spectrum is subdivided into sections based upon the type of vibration being studied. A comparison may be made with the published spectra of Kampf et al. [2]. A comparison may also be made with the spectrum downloaded from the RRUFF data base.

The Raman spectrum of plumbophyllite over the 1200$900 \mathrm{~cm}^{-1}$ spectral range is shown in Fig. 4a. The spectrum is dominated by an intense Raman band at $1027 \mathrm{~cm}^{-1}$. In the work published by Kampf et al. [2], the peak was located at $1025 \mathrm{~cm}^{-1}$. In this work, the spectra were curve fitted, in the work of Kampf et al., the spectra were simply taken as the as produced spectrum. Essentially, the two sets of data (this work and the work of Kampf are the same). There is a spectrum of plumbophyllite published in the RRUFF data base. No band was found at $1027 \mathrm{~cm}^{-1}$ in the RRUFF data base (please see the spectrum in the supplementary information). The spectrum of plumbophyllite in this work, together with the spectrum of Kampf et al. [2] is very different to that published on the RRUFF data base. This work brings into question the spectrum of plumbophyllite published on the RRUFF data base.

This band at $1027 \mathrm{~cm}^{-1}$ is assigned to the $\mathrm{SiO}$ symmetric stretching vibration of the $\left(\mathrm{SiO}_{3}\right)_{n}$ units. A series of low intensity bands may be observed at 926,956 , and $972 \mathrm{~cm}^{-1}$. A second series of low intensity Raman bands are observed at 1095, 1137 and $1153 \mathrm{~cm}^{-1}$. These bands are attributed to assigned to the SiO antisymmetric stretching vibration of the $\left(\mathrm{SiO}_{3}\right)_{n}$ units. A comparison of the Raman spectrum may be made with the published paper by Kampf et al. [2]. A comparison may be made with the spectrum of apophyllite. The Raman spectrum of plumbophyllite shows a strong Raman band at around this position. An intense Raman band
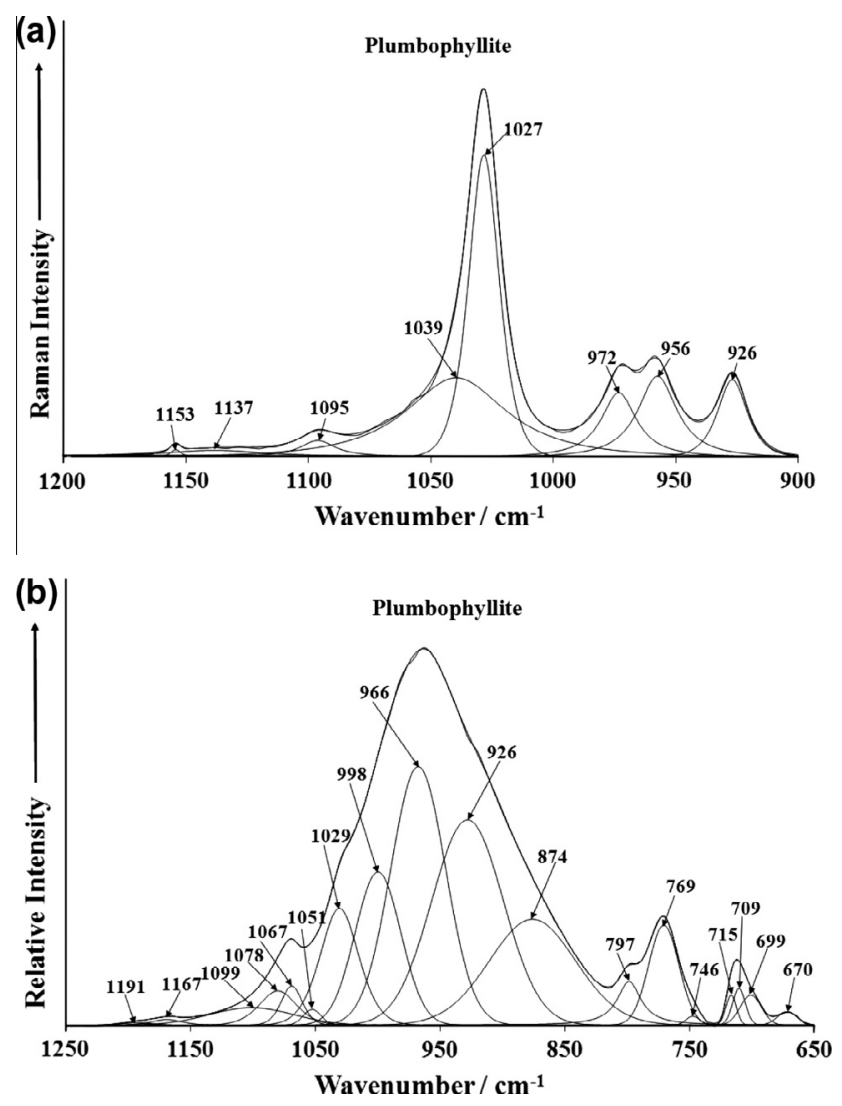

Fig. 4. (a) Raman spectrum of plumbophyllite over the $1400-800 \mathrm{~cm}^{-1}$ spectral range and (b) Infrared spectrum of plumbophyllite over the $1300-500 \mathrm{~cm}^{-1}$ spectral range. 
is shown at around $1025 \mathrm{~cm}^{-1}$ in the spectrum of Kampf et al. However, it is difficult to make and comparison without the defining of the peak positions.

There is a strong resemblance between the structure of plumbophyllite and the apophyllite minerals. The infrared spectrum of plumbophyllite over the $1250-650 \mathrm{~cm}^{-1}$ spectral range is shown in Fig. $4 \mathrm{~b}$. The spectrum is complex with many overlapping bands. A broad spectral feature is observed at around $966 \mathrm{~cm}^{-1}$. All of these bands between say 850 and $1250 \mathrm{~cm}^{-1}$ are attributed to $\mathrm{SiO}$ antisymmetric stretching vibration of the $\left(\mathrm{SiO}_{3}\right)_{n}$ units. An intense band for apophyllite is observed at around $1000 \mathrm{~cm}^{-1}$ and it may be decomposed into component bands at 963, 1005 and $1042 \mathrm{~cm}^{-1}$. Two sharp bands are observed at 1093 and $1120 \mathrm{~cm}^{-1}$. Two infrared bands are observed at 762 and $790 \mathrm{~cm}^{-1}$. These bands are assigned to the $E_{\mathrm{u}}$ mode. Kampf et al. [2] showed infrared peaks at shows prominent features at 958, $771,711,640,499,465$, and $439 \mathrm{~cm}^{-1}$. Kampf et al. attributed these infrared bands in the main to silicate peaks without defining the assignment of these peaks.

Kampf et al. [2] suggested that there was a similarity between the structure of pentagonite and plumbophyllite. The structure of plumbophyllite is based upon silicate sheets consisting of zigzag pyroxene-like $\left(\mathrm{SiO}_{3}\right)_{n}$ chains joined laterally into sheets with the unshared tetrahedral apices in successive chains. Many phyllosilicates are based on six-member rings. The Raman spectrum of apophyllite-(KF) is dominated by a very intense sharp peak at $1059 \mathrm{~cm}^{-1}$. Dowty showed that the $-\mathrm{SiO}_{3}$ units had a unique band position of $980 \mathrm{~cm}^{-1}$ [17] (see Figs. 2 and 4 of this reference). Dowty also showed that $\mathrm{Si}_{2} \mathrm{O}_{5}$ units had a Raman peak at around $1100 \mathrm{~cm}^{-1}$. Apophyllite-(KF) consists of continuous sheets of $\mathrm{Si}_{2} \mathrm{O}_{6}$ parallel to the 001 plane. The band at $1059 \mathrm{~cm}^{-1}$ is assigned to the $\mathrm{SiO}$ stretching vibration of these $\mathrm{Si}_{2} \mathrm{O}_{6}$ units. Adams et al. [7] reported the single crystal Raman spectrum of apophyllite. Adams and co-workers reported the factor group analysis of apophyllite. Based upon Adams [7] assignment this band is the $A_{1 g}$ mode. It is predicted that there should be three $A_{1 g}$ modes. However, only one is observed, perhaps because of accidental coincidence. Narayanan [18] collected the spectrum of an apophyllite mineral but did not assign any bands. Raman bands of significantly lower intensity are observed at 970,1007, 1043, 1086 and $1114 \mathrm{~cm}^{-1}$. The Raman bands at 1043,1086 and $1114 \mathrm{~cm}^{-1}$ are assigned to the $A_{2 \mathrm{u}}$ modes. Vierne and Brunel [19] published the single crystal infrared spectrum of apophyllite and found the two $A_{2}$ modes, at 1048 and $1129 \mathrm{~cm}^{-1}$. The significance of this observation is that it shows that both the $\mathrm{Si}-\mathrm{O}$ bridge and terminal bonds yield stretching wavenumbers at comparable positions. The Raman spectrum of apophyllite-(KF) from South Africa shows an intense band at $1059 \mathrm{~cm}^{-1}$ with bands of lower intensity at 1007, 1088 and $1114 \mathrm{~cm}^{-1}$. The band at $846 \mathrm{~cm}^{-1}$ is assigned to a water librational mode. The Raman spectrum of the apophyllite-( $\mathrm{KOH})$ displays an intense band at $1057 \mathrm{~cm}^{-1}$ with bands of lower intensity at $851,969,1007$ and $1113 \mathrm{~cm}^{-1}$. The band of apophyllite$(\mathrm{KOH})$ at $1059 \mathrm{~cm}^{-1}$ is assigned to the $\mathrm{SiO}$ stretching vibration of the $\mathrm{Si}_{2} \mathrm{O}_{6}$ units. The band at $851 \mathrm{~cm}^{-1}$ is assigned to the water librational mode.

It is likely that the infrared bands in the spectrum of plumbophyllite at 769 and $797 \mathrm{~cm}^{-1}$ are due to water librational modes (Fig. 2b).

The Raman spectrum of plumbophyllite in the $700-300 \mathrm{~cm}^{-1}$ spectral range is shown in Fig. 5a. The spectrum is dominated by an intense Raman band at $643 \mathrm{~cm}^{-1}$. In the paper by Kampf et al. [2], the band was found at $641 \mathrm{~cm}^{-1}$. Thus, there is excellent agreement between the position of the bands reported in this work and that of Kampf et al. [2]. The spectrum of plumbophyllite given in the RRUFF data base does not show a peak in this position. It does show a very low intensity band at $625 \mathrm{~cm}^{-1}$. The spectrum of
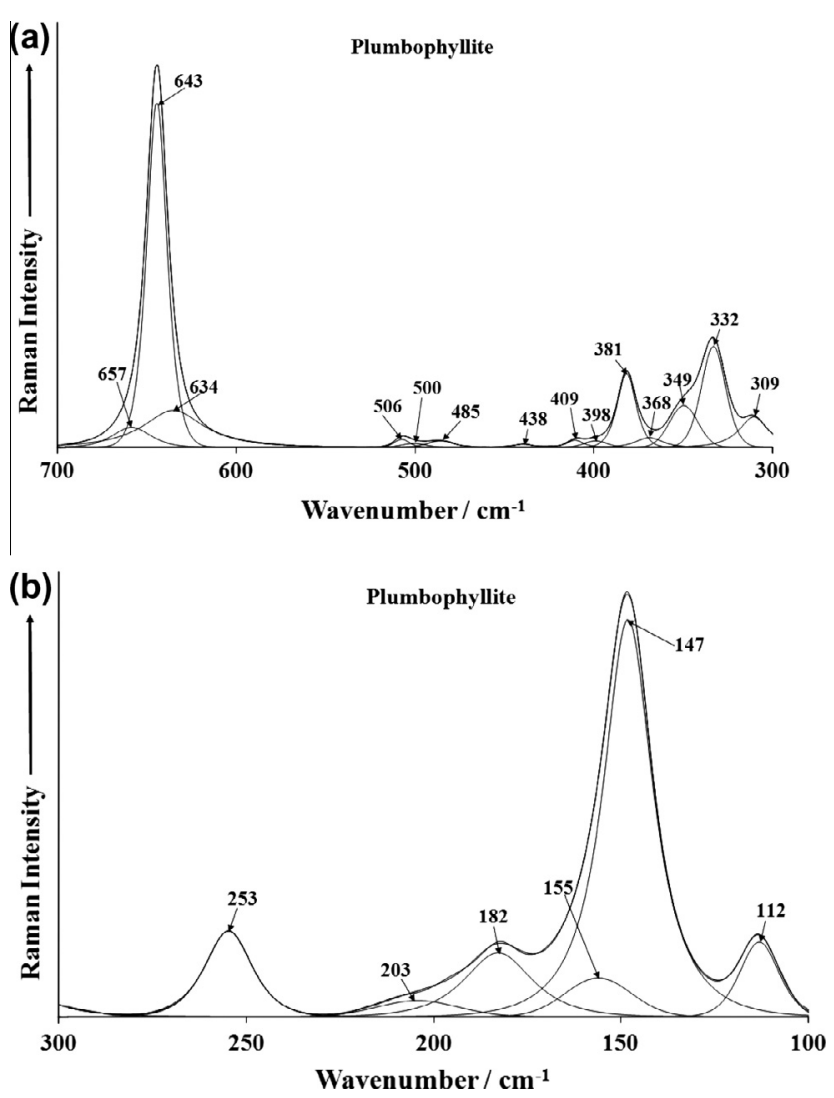

Fig. 5. (a) Raman spectrum of plumbophyllite over the $800-300 \mathrm{~cm}^{-1}$ spectral range and (b) Raman spectrum of plumbophyllite over the $300-100 \mathrm{~cm}^{-1}$ spectral range.

plumbophyllite in this work, together with the spectrum of Kampf et al. is very different to that published on the RRUFF data base. This work brings into question the spectrum of plumbophyllite published on the RRUFF data base. This band at $643 \mathrm{~cm}^{-1}$ is assigned to OSiO bending vibrations of the $\left(\mathrm{SiO}_{3}\right)_{n}$ units. Raman bands of low intensity are observed at 485, 500 and $506 \mathrm{~cm}^{-1}$. These bands are assigned to the flexing vibrations of the $\left(\mathrm{SiO}_{3}\right)_{n}$ sheets. A comparison of the Raman spectrum may be made with the published paper by Kampf et al. [2]. The Raman spectrum of plumbophyllite shows a strong Raman band at around this position. However, it is difficult to make and comparison without the defining of the peak positions. Raman bands at 309, 332, 349, $381 \mathrm{~cm}^{-1}$ and others in this spectral region are attributed to $\mathrm{PbO}$ stretching vibrations.

Raman bands for apophyllite are found at 431, 583 and $663 \mathrm{~cm}^{-1}$. These bands are assigned to OSiO bending modes. There are many more bands observed in the spectra shown in Fig. 3a than is required from theory. Raman bands of apophyllite are observed at $337,373,462,485,511,538 \mathrm{~cm}^{-1}$ in the region below $550 \mathrm{~cm}^{-1}$. Dowty calculated the band position of these bending modes for different siloxane units [17]. Dowty demonstrated the band position of the bending modes for $\mathrm{SiO}_{3}$ units at around $650 \mathrm{~cm}^{-1}$. This calculated value is in harmony with the lower wavenumber band observed at $643 \mathrm{~cm}^{-1}$ for plumbophyllite. According to Adams et al. [7] the band at $432 \mathrm{~cm}^{-1}$ is due to the coincidence of both the $B_{2 \mathrm{~g}}$ and $E_{\mathrm{g}}$ modes.

The Raman spectrum of plumbophyllite in the far low wavenumber region is reported in Fig. 5b. An intense Raman band is observed at $147 \mathrm{~cm}^{-1}$ with Raman bands of lesser intensity at 112 , 182 and $253 \mathrm{~cm}^{-1}$. These bands are described simply as lattice vibrations. For the apophyllite mineral, quite intense Raman bands 
are observed at 106, 132, 161, 155, 209, 228 and $266 \mathrm{~cm}^{-1}$. Strong Raman bands were also reported by Adams et al. [7] in the single crystal Raman spectrum of apophyllite in this spectral region. Adams et al. showed the orientation dependence of the spectra. Bands in these positions are due to framework vibrations and probably also involve water. The intense band at $209 \mathrm{~cm}^{-1}$ may involve hydrogen bonding of water. However until the Raman spectrum of deuterated apophyllite is measured, then no firm conclusion can be made. Raman bands are observed for the apophyllite-(KOH) at 106 , $121,134,163,185,203,236$ and $254 \mathrm{~cm}^{-1}$.

Both the Raman and infrared spectra as illustrated in Fig. 3, clearly show the presence of $\mathrm{OH}$ stretching vibrations. The Raman spectrum of plumbophyllite over the $3000-3700 \mathrm{~cm}^{-1}$ spectral range is shown in Fig. 6a. This spectrum displays a broad spectral profile and component bands may be resolved at 3215, 3470, 3494 and $3567 \mathrm{~cm}^{-1}$. In the work of Kampf et al., Raman bands were noted at 3209, 3338, 3468 and 3561 . The results of our work are in excellent agreement with the work of Kampf et al. The differences in peak position may be simply due to the peak fitting of the Raman bands in this work. In the Raman spectrum of plumbophyllite downloaded from the RRUFF data base, peaks were located at $2675,3022,3192,3346,3457$ and $3700 \mathrm{~cm}^{-1}$. There does not appear to be much correspondence between the peak positions observed in this work with those of the RRUFF data base spectrum. This work together with the work of Kampf et al. brings into question the validity of the spectrum of plumbophyllite from the RRUFF data base. The formula of plumbophyllite $\mathrm{Pb}_{2} \mathrm{Si}_{4} \mathrm{O}_{10} \cdot \mathrm{H}_{2} \mathrm{O}$ is such that one water molecule is noted per formula unit. The above bands at $3215,3470,3494$ and $3567 \mathrm{~cm}^{-1}$ are attributed to the stretching vibrations of water. The observation of multiple water stretching vibrations indicates that water is in different molecular environments with different degrees of hydrogen bonding. The Raman band at $3215 \mathrm{~cm}^{-1}$ is indicative of strong hydrogen bonding
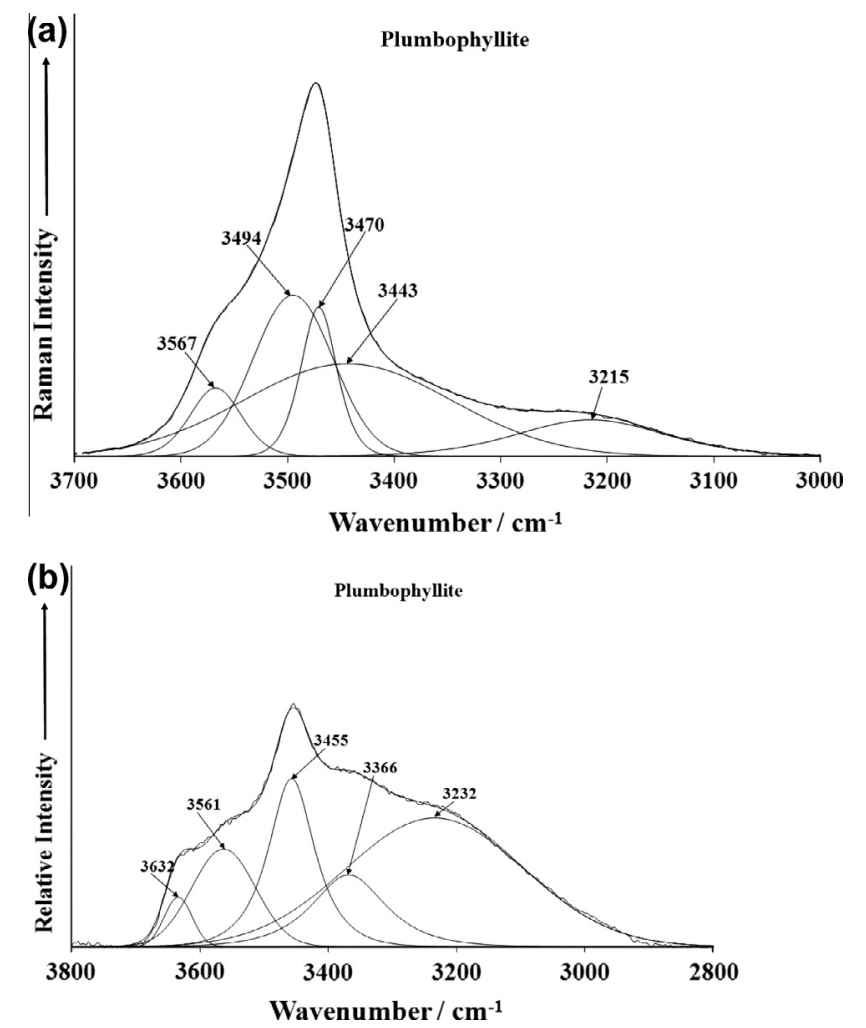

Fig. 6. (a) Raman spectrum of plumbophyllite over the $4000-2600 \mathrm{~cm}^{-1}$ spectral range and (b) Infrared spectrum of plumbophyllite over the $4000-2600 \mathrm{~cm}^{-1}$ spectral range. whereas the band at $3567 \mathrm{~cm}^{-1}$ is indicative of weak hydrogen bonding. Kampf et al. [2] also suggested that there were two independent water molecules in the structure of plumbophyllite which are oriented perpendicular to the $b$ axis.

The infrared spectrum of plumbophyllite is displayed in Fig. 6b. Infrared bands may be resolved at 3232, 3366, 3455, 3561 and $3632 \mathrm{~cm}^{-1}$ and are assigned to water stretching vibrations. The number and complexity of the infrared spectrum in the water stretching region is reflected in the water bending region (Fig. 7). The spectrum shows complexity and infrared bands may be resolved at $1607,1627,1659$ and $1686 \mathrm{~cm}^{-1}$. The position of these bands shows that water is involved in the structure of plumbophyllite with different hydrogen bond strengths.

A comparison may be made with the spectra of plumbophyllite and apophyllite. Overall two features are observed for apophyllite, namely bands due to water stretching vibrations and hydroxyl stretching bands. It is noted that the hydroxyapophyllite Raman spectrum has two $\mathrm{OH}$ stretching bands. The Raman spectrum of the apophyllite from India shows a complex set of bands which may be resolved into component bands at 2813, 2893, 3007, 3085 and $3365 \mathrm{~cm}^{-1}$. These bands are attributed to water stretching vibrations. Neutron diffraction studies have shown that water is hydrogen bonded to the silicate framework structure [20]. In the model of Prince [20] approximately one-eighth of the water molecules are replaced by $\mathrm{OH}^{-}$and the remaining protons bonded to fluoride to form HF molecules. Both $\mathrm{OH}^{-}$and $\mathrm{H}_{2} \mathrm{O}$ are hydrogen bonded to the silicate framework. Bartl and Pfeifer [21] presented a model of apophyllite in which some hydroxyl units are replaced by fluoride ions. This model seems more appropriate as the sizes of $\mathrm{F}^{-}$ and $\mathrm{OH}^{-}$ions are very close. There are many examples in nature where in minerals the $\mathrm{OH}^{-}$units are either completely or partially replaced by $\mathrm{F}^{-}$ions. Different hydrogen bond strengths are observed. The intense band at $3557 \mathrm{~cm}^{-1}$ and a low intensity band at $3626 \mathrm{~cm}^{-1}$ are assigned to the stretching vibrations of the $\mathrm{OH}$ units. In contrast, the Raman spectrum of the fluorapophyllite from South Africa shows an extremely intense band at $3557 \mathrm{~cm}^{-1}$ which is attributed to the $\mathrm{OH}$ stretching vibration. Because the intensity of this band is so high, it makes the intensity of the water bands appear low. Water bands are found at 2848, 3009, 3098 and $3430 \mathrm{~cm}^{-1}$. The difference between the two apophyllite-(KF) mineral samples may be due to the amount of $\mathrm{OH}$ substitution by $\mathrm{F}^{-}$ions. Based upon the intensity of the Raman peaks, it appears that there is a lot more $\mathrm{OH}$ in the South African sample. In the apophyllite- $(\mathrm{KOH})$ sample from Arizona, two $\mathrm{OH}$ stretching vibrations are observed at 3563 and $3625 \mathrm{~cm}^{-1}$. It is proposed that the difference between apophyllite-(KF) and apophyllite-( $\mathrm{KOH})$ is the observation of two bands in the $\mathrm{OH}$ stretching region at around 3563

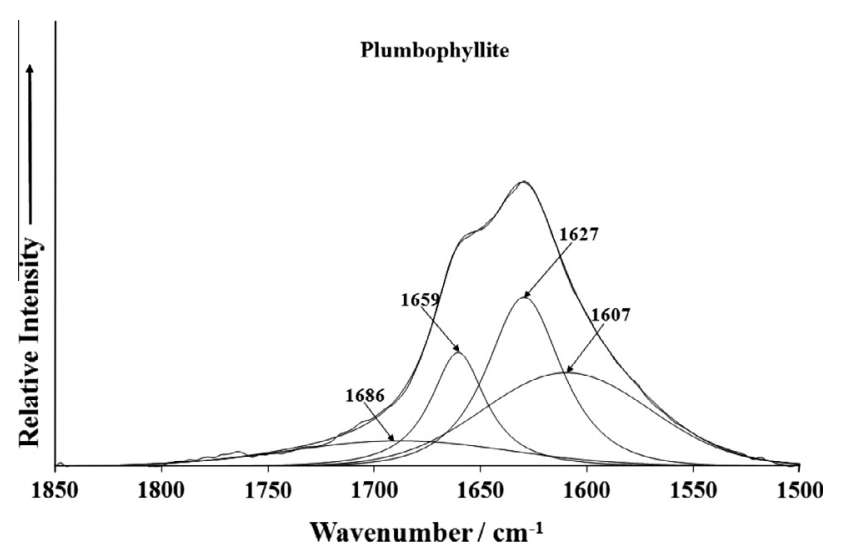

Fig. 7. Infrared spectrum of plumbophyllite (lower spectrum) in the 1850$1500 \mathrm{~cm}^{-1}$ spectral range. 
and $3625 \mathrm{~cm}^{-1}$. The Raman spectrum of the water stretching region also shows considerable complexity as was observed for the first two apophyllite samples. Water stretching bands are observed at 2812, 2974, 3062, 3212 and $3357 \mathrm{~cm}^{-1}$. Chukhrov et al. [22] determined the nature of water in apophyllites and showed the water was in a highly crystalline state.

\section{Conclusions}

The studied sample is composed by mainly composed by $\mathrm{Si}$ and $\mathrm{Pb}$, with minor amounts of $\mathrm{Zn}$ in substitution to lead. Unidentified clay mineral also occurs in association with plumbophyllite. The molecular structure of the silicate mineral plumbophyllite has been studied using Raman and infrared spectroscopy. The structure consists of undulating sheets of silicate tetrahedra between which are located $\mathrm{Pb}$ atoms and channels containing $\mathrm{H}_{2} \mathrm{O}$. The silicate sheets can be described as consisting of zigzag pyroxene-like $\left(\mathrm{SiO}_{3}\right)_{n}$ chains joined laterally into sheets with the unshared tetrahedral apices in successive chains pointed alternately up and down, a configuration also found in apophyllite and pentagonite.

Raman and infrared bands are assigned to the stretching and bending vibrations of the $\left(\mathrm{SiO}_{3}\right)_{n}$ units. Complexity is found in both the Raman and infrared spectra of the $\mathrm{OH}$ stretching region. Multiple bands may be resolved in these spectra; thus, water in differing molecular environments is proposed.

\section{Acknowledgements}

The financial and infra-structure support of the Discipline of Nanotechnology and Molecular Science, Science and Engineering Faculty of the Queensland University of Technology, is gratefully acknowledged. The Australian Research Council (ARC) is thanked for funding the instrumentation. The authors would like to acknowledge the Center of Microscopy at the Universidade Federal de Minas Gerais (http://www.microscopia.ufmg.br) for providing the equipment and technical support for experiments involving electron microscopy. The authors are also grateful to CNPq Project 402852/2012-5.

\section{Appendix A. Supplementary data}

Supplementary data associated with this article can be found, in the online version, at http://dx.doi.org/10.1016/j.saa.2014.02.181.

\section{References}

[1] A.R. Kampf, R.M. Housley, Am. Mineral. 96 (2011) 423-429.

[2] A.R. Kampf, G.R. Rossman, R.M. Housley, Am. Mineral. 94 (2009) 1198-1204.

[3] R.L. Frost, Y. Xi, Spectrochim. Acta A95 (2012) 263-269.

[4] H.T. Evans Jr., Am. Mineral. 58 (1973) 412-424.

[5] S.K. Sengupta, A.K. Chakravarty, G.C. Maiti, Fertilizer Technol. 20 (1983) 52-54.

[6] T.A. Sidorov, Zh. Neorg, Khim 52 (2007) 1688-1696.

[7] D.M. Adams, R.S. Armstrong, S.P. Best, Inorg. Chem. 20 (1981) 1771-1776.

[8] C. Duval, J. Lecomte, J. Chim. Phys. 50 (1953) C64-C71.

[9] R.L. Frost, Y. Xi, R. Scholz, A. Lopez, F.M. Belotti, J. Mol. Struct. 1042 (2013) 1-7.

[10] R.L. Frost, Y. Xi, Spectrochim. Acta A91 (2012) 324-328.

[11] R.L. Frost, Y. Xi, J. Mol. Struct. 1028 (2012) 200-207.

[12] R.L. Frost, A. Lopez, Y. Xi, R. Scholz, L. Gandini Antonio, Spectrochim. Acta A118 (2014) 987-991.

[13] R.L. Frost, Y. Xi, R. Scholz, R.M.F. Lima, L.F.C. Horta, A. Lopez, Spectrochim. Acta A115 (2013) 376-381.

[14] R.L. Frost, Y. Xi, J. Therm, Anal. Calorim. 112 (2013) 615-619.

[15] R.L. Frost, Y. Xi, J. Mol. Struct. 1018 (2012) 72-77.

[16] R.L. Frost, Y. Xi, Spectrochim. Acta A89 (2012) 88-92.

[17] E. Dowty, Phys. Chem. Miner. 14 (1987) 80-93.

[18] P.S. Narayanan, Curr. Sci. 20 (1951) 94-95.

[19] R. Vierne, R. Brunel, Bull. Soc. France Mineral. Crist. 92 (1969) 409-419.

[20] E. Prince, Am. Mineral. 56 (1971) 1241-1249.

[21] H. Bartl, G. Pfeifer, Fortschr. Mineral. 53 (1975) 3.

[22] F.V. Chukhrov, L.P. Ermilova, E.S. Rudnitskaya, Trudy Min. Muz. Akad. Nauk SSSR 20 (1971) 221-225. 